\title{
Persistent Long-Term Synaptic Plasticity Requires Activation of a New Signaling Pathway by Additional Stimuli
}

\author{
Jiang-Yuan Hu, Orit Baussi, Amir Levine, Yang Chen, and Samuel Schacher \\ Department of Neuroscience, Columbia University College of Physicians and Surgeons, New York State Psychiatric Institute, New York, New York 10032
}

\begin{abstract}
Most memories are strengthened by additional stimuli, but it is unclear how additional stimulation or training reinforces long-term memory. To address this we examined whether long-term facilitation (LTF) of Aplysia sensorimotor synapses in cell culture-a cellular correlate of long-term sensitization of defensive withdrawal reflexes in Aplysia californica - can be prolonged by additional stimulation. We found that $1 \mathrm{~d}$ treatment with serotonin (5-HT; five brief applications at 20 min intervals) produced LTF lasting $\sim 3 \mathrm{~d}$, whereas $2 \mathrm{~d}$ of such 5 -HT treatments induced a persistent LTF lasting $>7 \mathrm{~d}$. Incubation with the protein synthesis inhibitor rapamycin during the second set of 5-HT treatments abolished all facilitation, and synapse strength returned prematurely to baseline. Persistent LTF required more persistent elevation in the expression of the neurotrophin-like peptide sensorin and its secretion. Activation of protein kinase $\mathrm{C}$ (PKC) during the second day of 5-HT treatments, not required for LTF or changes in sensorin expression during the first set of 5-HT treatments, is critical for persistent LTF and replaces phosphoinositide 3 kinase (PI3K) activity in mediating the increase in sensorin expression. In contrast, activations of PKC during the first day of 5-HT treatments and PI3K during the second day of 5-HT treatments are unnecessary for persistent LTF or the increases in sensorin expression. Thus, additional stimuli make preexisting plasticity labile as they recruit a new signaling cascade to regulate the synthesis of a neurotrophin-like peptide required for persistent alterations in synaptic efficacy.
\end{abstract}

\section{Introduction}

The duration and amplitude of many forms of long-term memory are reinforced with additional training given on successive days (McGaugh, 2000; Kandel, 2001; Wang et al., 2006; Xu et al., 2009). It is unclear whether these additional stimuli produce more persistent forms of long-term memory or cellular plasticity by regulating the same molecular and cellular changes initiated with the earlier stimuli or by activating new pathways.

The acquisition and consolidation of long-term memories require new gene expression and protein synthesis to alter the physiological or structural properties of the neurons and synapses activated by the stimuli (Davis and Squire, 1984; Goelet et al., 1986; Nader et al., 2000; Abel and Lattal, 2001; Alberini, 2005; Reijmers et al., 2007). In Aplysia, $1 \mathrm{~d}$ of training (repeated stimuli), evoking the repeated release of serotonin (5-HT) (Glanzman et al., 1989; Marinesco and Carew, 2002), produces sensitization of defensive withdrawal reflexes lasting $\sim 3-4 \mathrm{~d}$, whereas multiday training results in sensitization lasting $>3$ weeks (Pinsker et al., 1973; Frost et al., 1985; Bailey and Chen, 1989; Kandel, 2001). Regardless of the duration, new macromolecular synthesis is required for the behavioral changes, synaptic facilitation, and

Received March 17, 2011; revised April 27, 2011; accepted April 29, 2011.

Author contributions: J.-Y.H. and S.S. designed research; J.-Y.H., 0.B., and Y.C. performed research; J.-Y.H. and A.L. analyzed data; J.-Y.H. and S.S. wrote the paper.

The work was supported by National Institutes of Health Grants MH 60387 and NS 42159. Animals were provided by the National Center for Research Resources for Aplysia at the University of Florida in Miami, which is supported by NIH Grant RR-10294. We thank Drs. John Koester and Wayne Sossin for their comments and suggestions.

Correspondence should be addressed to Jiang-Yuan Hu at the above address. E-mail: jh2004@columbia.edu. DOI:10.1523/JNEUROSCI.1358-11.2011

Copyright $\odot 2011$ the authors $\quad 0270-6474 / 11 / 318841-10 \$ 15.00 / 0$ structural changes in the sensory neurons (Castellucci et al., 1989; O'Leary et al., 1995; Bailey et al., 1992, 2008; Miniaci et al., 2008).

In cell culture, Aplysia sensorimotor synapses express several forms of synaptic facilitation (Montarolo et al., 1986; Rayport and Schacher, 1986; Eliot et al., 1994; Sun and Schacher, 1998; Miniaci et al., 2008). Five bath applications of 5-HT produce a protein synthesis- and mRNA synthesis-dependent long-term facilitation (LTF) accompanied by the formation of new synapses (Montarolo et al., 1986; Glanzman et al., 1990; Bailey et al., 1992). We therefore ask, do additional stimuli (a second day of five 5-HT applications) prolong the duration of LTF by enhancing the expression of the same molecules and the activation of the same cellular and molecular pathways as those activated by the first day of stimuli?

We found that additional exposure to 5-HT on the second day produced a more persistent LTF that prematurely returned to baseline when specific inhibitors were present during or immediately after the additional stimuli. The additional stimuli evoked a second round of rapid increase in the synthesis and secretion of the neurotrophin-like neuropeptide sensorin required for persistent LTF. Unlike the initial LTF, where activation of phosphoinositide 3 kinase (PI3K) mediated the rapid 5-HT-induced increase in sensorin synthesis required to initiate LTF (Hu et al., 2006), now activation of protein kinase $\mathrm{C}$ (PKC) by the additional stimuli mediates a persistent increase in sensorin. Thus, additional stimuli make existing LTF labile and induce a more persistent LTF by recruiting a new signaling pathway. The responses to additional stimuli at this behaviorally relevant synapse represent a cellular correlate that parallels aspects of memory consolidation and reconsolidation (Dudai, 2004; Nader and Einarsson, 2010; 
Alberini, 2011; Inda et al., 2011) and suggest that activation of new and old molecular pathways by additional stimuli in neurons already expressing synaptic plasticity contribute to the enhancement of long-term synaptic plasticity.

\section{Materials and Methods}

Cell culture and electrophysiology. Sensory neurons were isolated from pleural ganglia dissected from adult animals (60-80 g; Aplysia californica, which are hermaphrodite), and motor neuron L7s were isolated from abdominal ganglia dissected from juvenile animals (2 g). Animals were raised at the marine facility at the University of Miami, Florida, and shipped throughout the year. Cocultures contained one sensory neuron and one L7 maintained up to $11 \mathrm{~d}$. Standard electrophysiological techniques were used to record the EPSP amplitude evoked in L7 before and at different times after various treatments (Schacher and Montarolo, 1991; $\mathrm{Hu}$ et al., 2004a, 2006, 2007). In brief, an intracellular microelectrode (containing 2.0 м K-acetate, $0.5 \mathrm{~m} \mathrm{KCl}$, and $10 \mathrm{~mm}$ K-HEPES, $\mathrm{pH}$ 7.4) in L7 was used to monitor EPSPs after action potentials evoked with an extracellular electrode placed near the cell body of the sensory neurons. The membrane potential of the motor neuron L7 was held at $-80 \mathrm{mV}$. For measurement of persistence of LTF, EPSPs were recorded up to $7 \mathrm{~d}$ after the last treatment with 5-HT.

Drug treatments. Drug treatments [5-HT, inhibitors, or anti-sensorin antibody (SEN Ab)] were applied to 4-, 5-, or 6-d-old culture (defined as day 0, day 1, or day 2 in the timeline for all experimental protocols, respectively). Each set of 5 -HT treatments consisted of five bath applications of $5 \mu \mathrm{M} 5$-HT, each lasting $5 \mathrm{~min}$ at $20 \mathrm{~min}$ intervals. Cultures were treated with one set of 5 -HT treatments on day 1 or with two sets of 5-HT treatments on 2 successive days (day 0 and day 1 ). Protein synthesis inhibitor rapamycin (Rapa; $50 \mathrm{nm;} \mathrm{Sigma),} \mathrm{polyclonal} \mathrm{anti-sensorin} \mathrm{antibody}(400 \mathrm{ng} / \mathrm{ml})$, the PI3K inhibitor 2-(4-morpholinyl)-8-phenyl-4 H-1-benzopyran-4-one (LY294002) (PI3KI; $10 \mu \mathrm{M}$; Calbiochem), or PKC inhibitor chelyrethrine (10 $\mu \mathrm{M}$; Calbiochem) were added to cultures for $2 \mathrm{~h}$ during, before or after various treatments (see Results and timelines in figures). Rapamycin blocks the synthesis of some proteins, including the neuropeptide sensorin, and is rapidly reversible with washout (Hu et al., 2004a). The actions of the SEN Ab, PI3K, or PKC inhibitors are rapidly reversible (Hu et al., 2004a,b, 2006, 2007).

Immunocytochemistry. Immunocytochemistry was used to monitor the expression of sensorin in the sensory neurons. Cultures were rinsed briefly in artificial seawater and fixed in $4 \%$ paraformaldehyde and processed as described previously (Liu et al., 2003; Hu et al., 2004b, 2006). Cells were exposed to rabbit polyclonal antibody specific for sensorin ( $1: 1000)$ diluted in $2 \%$ normal goat serum in $0.01 \mathrm{M}$ PBS with $0.3 \%$ Triton X-100 at $4^{\circ} \mathrm{C}$ for $24 \mathrm{~h}$. The incubated cultures were washed in 0.01 M PBS and incubated in FITC-conjugated goat anti-rabbit IgG (1:200; Sigma) at $4^{\circ} \mathrm{C}$ for $4 \mathrm{~h}$. After washing in $0.01 \mathrm{~m} \mathrm{PBS}$, cultures were imaged directly with a filter set for detecting fluorescent signal. To test the specificity of the primary antibody, controls were performed, including the substitution of normal rabbit serum for the primary antibody and omission of the primary antibody. All controls showed little immunocytochemical reaction.

Quantification and data analyses. All data are expressed as the mean \pm SEM produced by the indicated treatments. The EPSP amplitude was measured in millivolts. The changes in EPSP amplitudes after various treatments were measured by dividing the posttreatment EPSP ampli- tude by the pretreatment EPSP amplitude multiplied by $100 \%$. No change in amplitude is represented as $100 \%$. The intensity of sensorin immunostaining was tested by measuring average fluorescent intensity in the sensory neuron cell body, the entire original axon and axon stump, and the regenerated neurites and varicosities of sensory neurons contacting the original axons of L7 with the MCID (7.0) software package from Imaging Systems. Varicosities were defined as swellings along the sensory neuron neurites with diameters $\geq 1.5 \mu \mathrm{m}$. Sensorin staining intensities for the various experimental treatments were normalized to the intensities measured in each cellular compartment with control treatments (100\%). ANOVA was used to assess overall significant differences produced by treatment, and the Scheffe $F$ test was used to gauge significant differences between individual treatments.

\section{Results}

Additional stimuli produce persistent LTF sensitive to complete disruption by rapamycin

After $4 \mathrm{~d}$ in culture (defined as day 0 for all experimental protocols) (Fig. $1 A$ ), the strength of synapses between sensory neurons and motor neuron L7 achieve a steady-state baseline level. In the absence of any 5-HT treatment, EPSP amplitude is maintained over the next $7 \mathrm{~d}$ (Fig. 1B,C). We monitored the change in synaptic strength (EPSP amplitude) in mature cultures (day 0) after control applications $(n=8)$ and one set of 5-HT treatments (1 5 -HT; $n=9$ ) and compared them to the change in EPSP amplitude produced by two sets of 5-HT treatments (2 5-HT; $n=10$ ). The increase in EPSP amplitude $1 \mathrm{~d}$ after 15 -HT was $\sim 165 \%$ compared to that in the control treatment $(\sim 100 \%$; data not shown). By $2 \mathrm{~d}$ after 15 -HT (on day 3 in the timeline), the increase in EPSP amplitude was reduced but still significantly higher than control (139 $\pm 7.5 \%$ compared to $98 \pm 3.7 \%$; $p<$ 0.05 ). By day 7 , synaptic strength with 15 -HT was no longer 

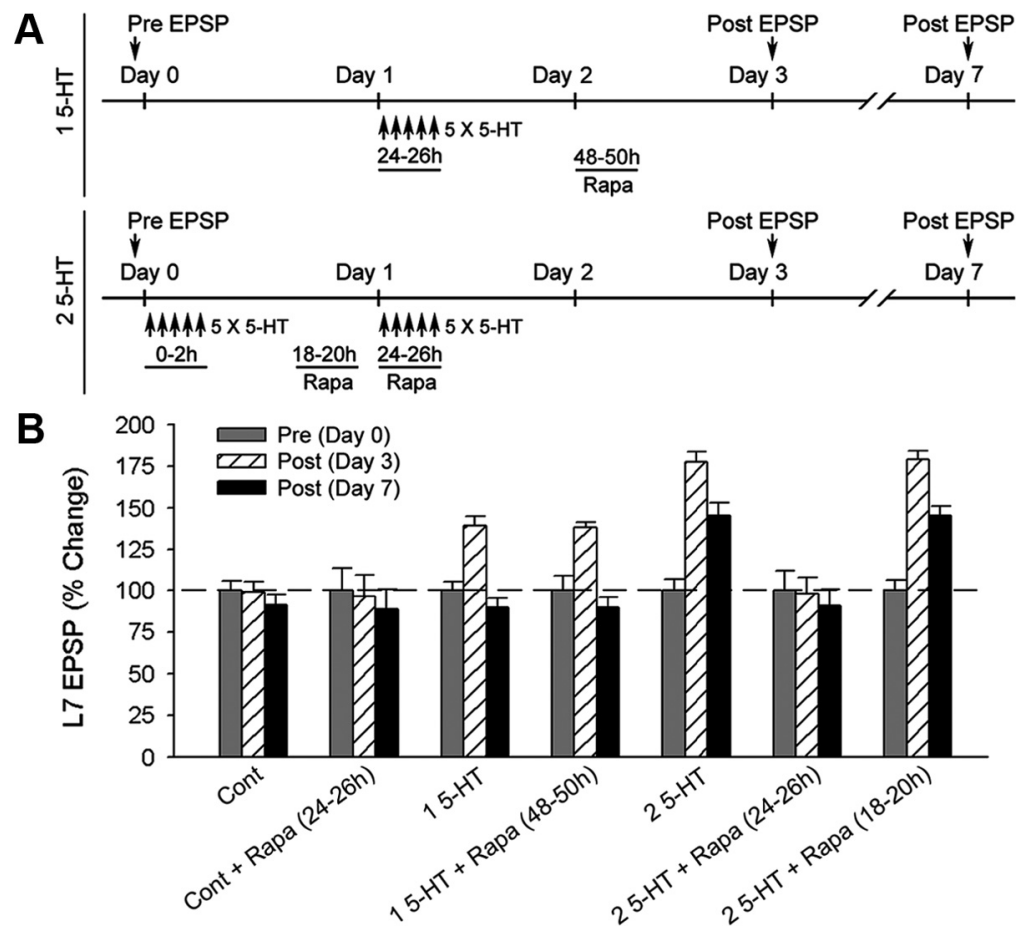

Figure 2. Rapamycin applied during the second set of 5-HT treatments blocked persistent LTF. A, Timeline of treatments indicating when $15-\mathrm{HT}, 25-\mathrm{HT}$, or Rapa was applied and EPSP amplitudes were tested. $\boldsymbol{B}$, Summary of the changes in EPSP amplitude in the indicated treatments. An ANOVA indicated a significant effect of treatment $(\mathrm{df}=12,94 ; F=52.272 ; p<0.001$ ). By individual comparisons, 15-HT, 15-HT + Rapa (48-50 h), 25-HT, and 25-HT + Rapa (18-20 h) significantly increased EPSP amplitude on day 3 compared to both control $(F=2.972,2.378,11.855$, and $10.298 ; p<0.05,0.05,0.01$, and 0.01 , respectively) and Cont + Rapa $(24-26 \mathrm{~h} ; F=2.726,2.576,10.081$, and $9.556 ; p<0.05,0.05,0.01$, and 0.01 , respectively). EPSP amplitude in 15-HT on day 3 was not different from that of $15-\mathrm{HT}+$ Rapa $(48-50 \mathrm{~h})$, but both were significantly smaller than those of $25-\mathrm{HT}$ $(F=2.804$ and $2.642 ; p<0.05)$ and $25-\mathrm{HT}+$ Rapa $(18-20 \mathrm{~h} ; F=2.771$ and 2.687 , respectively; $p<0.05)$. Rapamycin applied during the second set of 5-HT (24-26 h) significantly reduced the change in EPSP amplitude on day 3 back to control levels compared to $25-\mathrm{HT}$ or $25-\mathrm{HT}+$ Rapa $(18-20 \mathrm{~h} ; F=11.435$ or 9.191 , respectively; $p<0.01)$. EPSP amplitude in Cont + Rapa $(24-26 \mathrm{~h})$ or $25-\mathrm{HT}+$ Rapa $(24-26 \mathrm{~h})$ was not significantly different from that in control. The increase in EPSP amplitude produced by $25-\mathrm{HT}$ was not significantly different from the increase produced by $25-\mathrm{HT}+$ Rapa $(18-20 \mathrm{~h})$. By day 7 , only the increase in EPSP amplitude by $25-\mathrm{HT}$ or $25-\mathrm{HT}+$ Rapa $(18-20 \mathrm{~h})$ persisted significantly compared to others groups $(p<0.01)$ whereas the increase in EPSP amplitude with 25-HT was not significantly different from the increase with $25-\mathrm{HT}+\mathrm{Rapa}(18-20$ h). $5 \times 5$-HT, Five bath applications of $5 \mu \mathrm{m}$ 5-HT (each lasting $5 \mathrm{~min}$ ) at $20 \mathrm{~min}$ intervals.

significantly different from control (EPSP amplitude $93 \pm 9.0 \%$ compared to $92 \pm 4.4 \%$ for control). In contrast, cultures treated with 2 5-HT expressed a persistent LTF lasting $>7 \mathrm{~d}$. EPSP amplitude on day 3 ( $2 \mathrm{~d}$ after the last 5 -HT treatment) increased to $173 \pm 11.4 \%$ and was significantly greater than that of control $(p<0.01)$, and the increase was significantly higher than the increase in EPSP amplitude at the same time point produced by 1 5 -HT $(p<0.05)$. On day 7 , the increase in EPSP amplitude after 25 -HT persisted $(146 \pm 9.8 \%)$ and was significantly greater than that of both control and 15 -HT treatments $(p<0.01)$. Thus, adding a second set of 5-HT treatments both enhances the amplitude and prolongs the duration of LTF at sensory neuron synapses.

The rapidly reversible protein synthesis inhibitor rapamycin (50 nM) blocks LTF produced by $15-\mathrm{HT}$ when applied selectively during the 5-HT applications (Hu et al., 2006). We examined whether blocking protein synthesis transiently with rapamycin during the second set of 5-HT applications blocked the enhancement of facilitation produced by the second set of 5-HT treatments (Fig. 2). As additional controls, we compared the consequences on LTF of applying rapamycin a few hours before the second set of 5-HT treatments or $24 \mathrm{~h}$ after a single set of 5-HT treatments but without the presentation of the second set of
5-HT treatments. When rapamycin was present during the second set of 5-HT treatments [2 5-HT + Rapa $(24-26 \mathrm{~h})$; $n=8]$, it not only blocked the expected increase in EPSP amplitude produced by the second set of 5-HT treatments but also evoked a rapid return of EPSP amplitude to baseline levels on day 3 (98 $\pm 9.5 \%$ ), which was no longer significantly different from the change observed for control $(99 \pm 6.0 \% ; n=9)$ or control with rapamycin [Cont + Rapa (24-26 h); $97 \pm$ $12.9 \% ; n=6]$. In addition, the EPSP amplitude was reduced significantly such that it was significantly lower than the change produced by $15-\mathrm{HT}(139 \pm 5.1 \%$; $p<0.05 ; n=9$ ) or 15 -HT with rapamycin added $24 \mathrm{~h}$ after the single set of 5 -HT treatments (48-50 h; $138 \pm 3.0 \%$; $p<$ $0.05 ; n=6$ ). The LTF produced by 25 -HT on day $3(177 \pm 6.1 \% ; n=10)$ was significantly greater than the changes produced by the various control treatments $(p<$ $0.01)$ and the various $15-\mathrm{HT}$ treatments $(p<0.05)$. Application of rapamycin $4-6 \mathrm{~h}$ before the second set of 5 -HT treatments [2 5-HT + Rapa $(18-20 \mathrm{~h}), n=6]$ and protein synthesis resuming did not interfere with the expected increase (179 \pm $5.2 \%)$ in EPSP amplitude produced by 2 5 -HT, which was significantly greater $(p<$ $0.01)$ than that of control $(99 \pm 6.0 \%)$ or Cont + Rapa (24-26h; $97 \pm 12.9 \%)$. Treatment with rapamycin before the second set of 5-HT treatments also failed to interfere with persistent LTF on day 7 produced by 2 5-HT (146 $\pm 5.5 \%$ compared to $145 \pm$ $7.4 \%$ for $25-\mathrm{HT}$ ), which was significantly greater than the change in EPSP amplitude produced by $25-\mathrm{HT}+\mathrm{Rapa}(24-26 \mathrm{~h} ; 91 \pm$ $9.5 \% ; p<0.01$ ). Thus the second set of 5-HT treatments both prolongs LTF and makes preexisting LTF labile. In contrast, treatment with rapamycin $1 \mathrm{~d}$ after $15-\mathrm{HT}$ in the absence of the second set of 5-HT treatments did not affect LTF expressed on day 3. Thus, transient inhibition of protein synthesis completely disrupts preexisting long-term synaptic plasticity only when presented coincidently with the new stimuli.

\section{Persistent expression of sensorin and its secretion contribute to persistent LTF}

Sensorin is one of the newly synthesized proteins in sensory neurons that is required for LTF evoked by $15-\mathrm{HT}$ and whose synthesis is blocked by the presence of rapamycin (Hu et al., 2006). We next examined whether 25 -HT produced a persistent increase in sensorin that is sensitive to inhibition by rapamycin (Fig. 3).

Mature cultures were fixed and processed for sensorin immunochemistry on day 2, $24 \mathrm{~h}$ after the following treatments (Fig. $3 A)$ : (1) control treatments on day 0 and day $1(n=6)$, (2) control treatment on day 0 and one set of 5-HT treatments on day $1(n=6),(3)$ each set of 5-HT treatments both on day 0 and day $1(n=6)$, or $(4)$ one set of 5-HT treatments on day 0 and a second set of 5-HT treatments plus rapamycin on day $1(24-26 \mathrm{~h} ; n=6)$. 
A

Cont
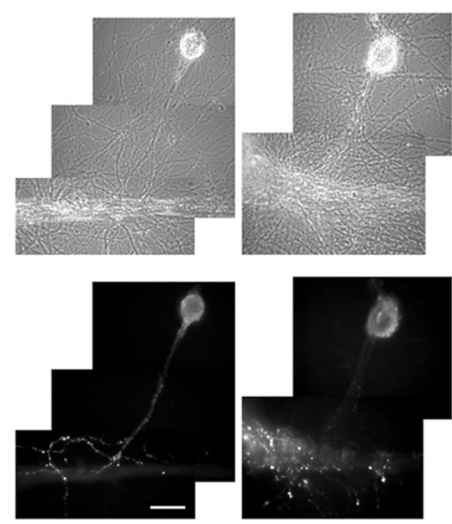

15-HT

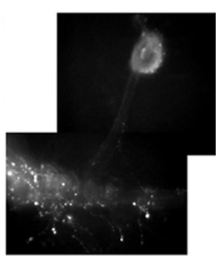

2 5-HT
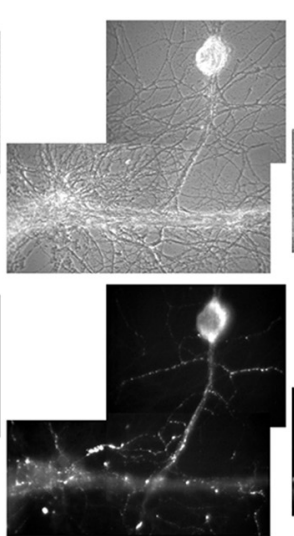

$25-\mathrm{HT}+$
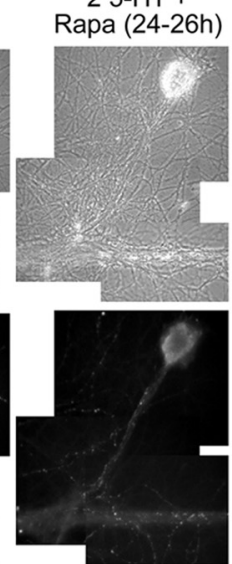

B

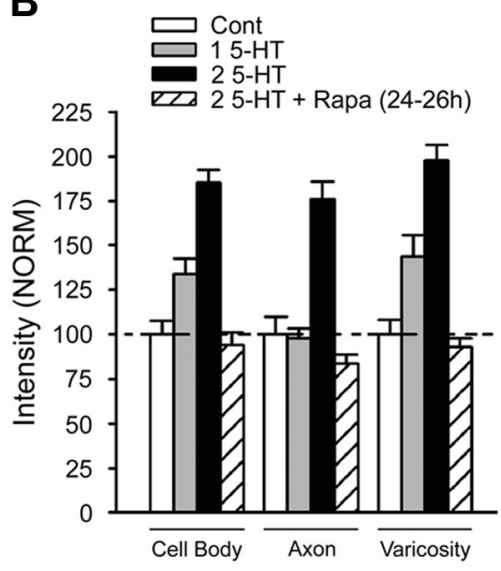

Figure 3. Additional 5-HT treatments evoked a rapamycin-dependent persistent increase in sensorin expression. $\boldsymbol{A}$, Cultures were fixed and processed for sensorin immunochemistry on day 2 , $24 \mathrm{~h}$ after the indicated treatments. Phase contrast (top) and epifluorescent views of sensorin staining (bottom) of the same area of sensory neurons (small cell bodies in top images) interacting with the main axons of the motor neuron are shown (extending from left to right). Treatment with rapamycin completely blocked the entire increase in sensorin staining back to control levels. Scale bar, $50 \mu \mathrm{m} . B$, Summary of the staining levels in the indicated compartments of the sensory neuron. An ANOVA indicated a significant effect of treatment (df $=6,40 ; F=4.915 ; p<0.001)$. Individual comparisons indicated that the following treatments produced a significant increase in sensorin expression compared to control normalized (NORM) as $100 \%$ : 15 - $\mathrm{HT}(F=3.32 ; p<0.05)$ and 25 - $\mathrm{HT}$ $(F=20.305 ; p<0.01)$ in the cell body; $25-\mathrm{HT}(F=16.038 ; p<0.01)$ in the axon; and $15-\mathrm{HT}(F=4.427 ; p<0.05)$ and 25 -HT $(F=22.055 ; p<0.01)$ in the varicosities. When rapamycin was added during the second set of 5 -HT treatments, sensorin staining in all compartments was not different from control and was significantly lower in all compartments compared to 25 -HT $(F=$ $23.376,23.74$ and 25.324 , respectively; $p<0.01)$ and significantly lower than the sensorin expression in the cell body and varicosities after 15 -HT $(F=4.626$ and $6.719 ; p<0.05$ and 0.01 , respectively).

Sensorin staining in three compartments of the sensory neuron (cell body, original axon, or regenerated varicosities) was measured, and staining in each compartment for the experimental groups was compared to the staining intensity of that compartment in the control (normalized to $100 \%$ ) (Fig. 3B). Compared to control, 15 -HT produced a small but significant increase $(p<$ $0.05)$ in sensorin expression in the sensory neuron cell body $(134 \pm 8.7 \%)$ and varicosities $(144 \pm 11.6 \%)$, but not in the axons $(98 \pm 5.4 \%)$. In contrast, 25 -HT produced a significant increase $(p<0.01)$ in sensorin staining in all compartments ( $185 \pm 7.1 \%$ in cell bodies, $176 \pm 9.8 \%$ in axons, and $198 \pm 8.3 \%$ in varicosities) compared to those compartments in both control and 15 -HT treatments. The increases in sensorin staining in all compartments were completely abolished ( $94 \pm 7.1 \%$ in cell bodies, $84 \pm 4.5 \%$ in axons, and $93 \pm 4.7 \%$ in varicosities) when rapamycin was present during the second set of 5-HT treatments (Fig. 3B). Sensorin staining in cell bodies and varicosities of sensory neurons in cultures treated with rapamycin during the second set of 5-HT treatments was significantly lower than the staining in those compartments for cultures treated with $15-\mathrm{HT}$ $(p<0.05)$. Thus, the return to baseline levels of sensorin expression on day 2 ( $1 \mathrm{~d}$ after the second set of 5-HT treatments) parallels the return to baseline levels of EPSP amplitude when rapamycin is present during the second set of 5-HT treatments (Fig. 2).

Sensorin secretion immediately after 15 -HT is required for LTF (Hu et al., 2004a, 2006). We therefore examined whether the downstream actions of secreted sensorin immediately after the second set of 5-HT treatments contributes to persistent LTF. We added SEN Ab to the bath for $2 \mathrm{~h}$ to bind up any secreted sensorin at the indicated times before or after 25 -HT or after control and 1 5-HT treatments (Fig. 4A). Sensorin secretion immediately after the second set of 5-HT treatments is also required for persistent LTF (Fig. $4 B$ ). The presence of exogenous SEN Ab immediately after the second set of 5-HT treatments [2 5-HT + SEN $\mathrm{Ab}(26-28 \mathrm{~h}) ; n=8$ ] abolished not only the additional increase in EPSP amplitudes produced by the second set of 5-HT treatments but also evoked a rapid return of EPSP amplitude to baseline levels on day $3(104 \pm 4.0 \%)$ compared to the change on day 3 produced by 25 -HT alone $(173 \pm 8.8 \% ; p<0.01 ; n=8)$, and the change in EPSP amplitude was no longer significantly different from that of control $(97 \pm 5.6 \% ; n=8)$ or control with SEN Ab $[$ Cont + SEN Ab $(26-28 \mathrm{~h}) ; 96 \pm 5.3 \% ; n=7]$. As expected $(\mathrm{Hu}$ et al., 2004a), transient treatment with SEN Ab at the same time period $24 \mathrm{~h}$ after 15 -HT [ 15 -HT + SEN Ab $(50-52 \mathrm{~h}) ; n=8$ ] failed to interfere with LTF produced by 15 -HT $(n=8)$ on day 3 $(138 \pm 7.2 \%$ compared to $139 \pm 7.8 \%$ for $15-\mathrm{HT})$. The increase in EPSP amplitudes on day 3 produced by 15 -HT or $15-\mathrm{HT}+$ SEN Ab $(50-52 \mathrm{~h})$ was significantly greater $(p<0.05)$ than that produced by $25-\mathrm{HT}+$ SEN Ab $(26-28 \mathrm{~h})$. A $2 \mathrm{~h}$ bath application of SEN Ab 4-6 h before the second set of 5-HT treatments [2 $5-\mathrm{HT}+\mathrm{SEN} \mathrm{Ab}(18-20 \mathrm{~h}) ; n=8$ ] did not affect the significant increase $(p<0.01)$ in EPSP amplitude on day 3 or on day 7 produced by 25 -HT ( $172 \pm 7.1 \%$ on day $3 ; 143 \pm 8.0$ on day 7$)$. Blocking the second round of interaction between newly synthesized sensorin with its receptors due to the timely competition with exogenous antibody not only blocked persistent LTF produced by adding a second set of 5-HT treatments but also produced a rapid return toward baseline. SEN Ab applied at the same time but in the absence of a second set of stimuli failed to affect existing LTF. Thus, the downstream signaling produced by the second round of secreted sensorin is required for persistent LTF and for maintaining preexisting LTF produced by the first set of 5-HT treatments.

\section{Activation of PKC, but not PI3K, by additional stimuli is required for persistent $L T F$ and persistent increase in sensorin expression}

With 15 -HT, the rapid increase in sensorin expression and the LTF expressed at $24 \mathrm{~h}$ require PI3K activity during the 5-HT applications but do not require PKC activity (Hu et al., 2004a, 2006). We therefore examined whether PI $3 \mathrm{~K}$ or PKC activity during the second set of 5-HT treatments is required for persistent LTF and the expression of sensorin. 

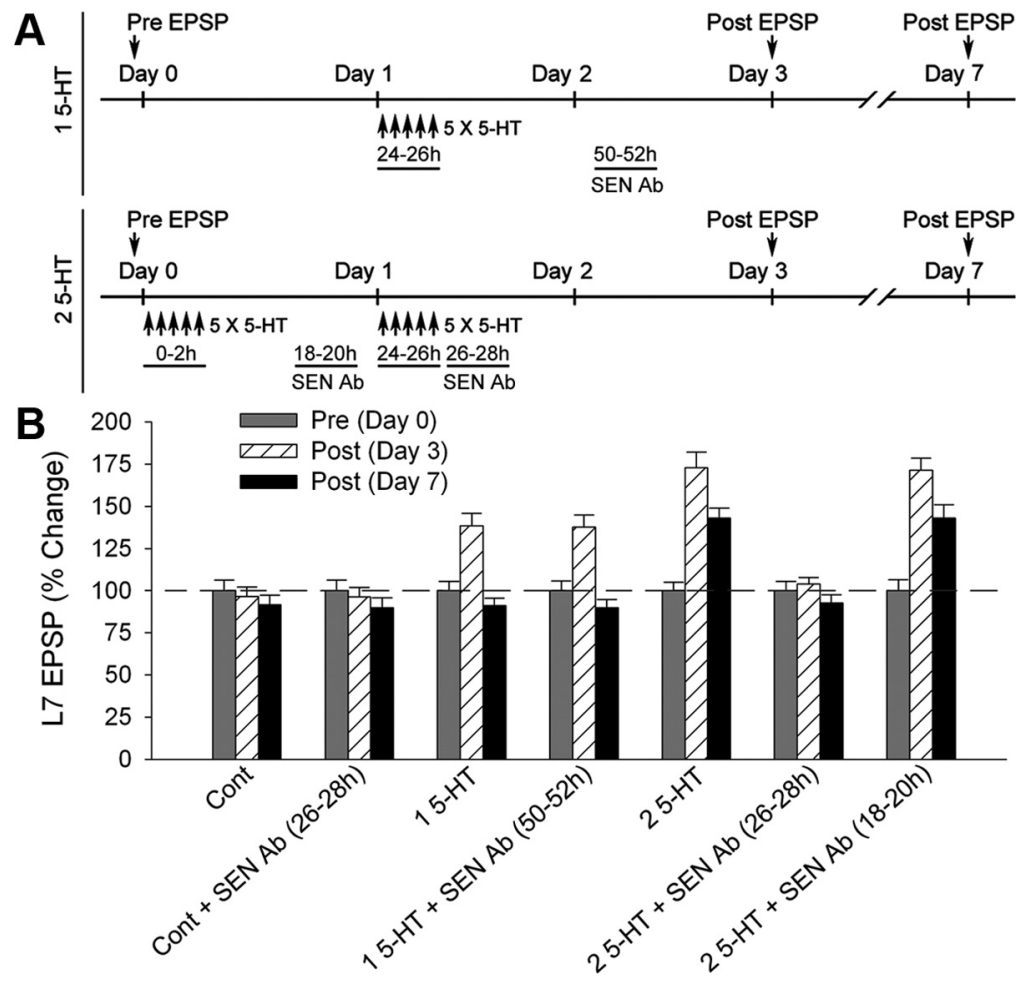

Figure 4. Sensorin secretion immediately after the second set of 5-HT treatments is required for persistent LTF. A, Timeline of treatments indicating when 15-HT, 25-HT, or SEN Ab was applied and EPSPs were tested. B, Summary of the changes in EPSP amplitude for the indicated treatments. An ANOVA indicated a significant effect of treatment (df $=12,96 ; F=40.653 ; p<$ 0.001). By individual comparisons, $15-\mathrm{HT}, 15-\mathrm{HT}+\mathrm{SEN} \mathrm{Ab}(50-52 \mathrm{~h}), 25-\mathrm{HT}$, and $25-\mathrm{HT}+\mathrm{SEN}$ Ab $(18-20 \mathrm{~h})$ significantly increased EPSP amplitude on day 3 compared to both control $(F=3.142,3.162,10.94$, and $9.628 ; p<0.05,0.05,0.01$, and 0.01 , respectively) and Cont $+\operatorname{SEN~Ab~}(26-28 \mathrm{~h} ; F=2.946,2.982,10.268$, and 9.113; $p<0.05,0.05,0.01$, and 0.01 , respectively). Changes in EPSP amplitudes on day 3 in 15 -HT was not different from that of 15 -HT + SEN Ab (50-52 h), but both were significantly smaller than those of $25-\mathrm{HT}(F=2.356$ and 2.349 , respectively; $p<0.05)$ and $25-\mathrm{HT}+\mathrm{SEN} \mathrm{Ab}(18-20 \mathrm{~h} ; F=2.339$ and 2.637, respectively; $p<0.05$ ). Two hour incubation of SEN Ab immediately after the second set of 5 -HT treatments significantly reduced the change in EPSP amplitude on day 3 back to control level compared to $25-\mathrm{HT}$ or $25-\mathrm{HT}+\mathrm{SEN} \mathrm{Ab}(18-20 \mathrm{~h} ; \mathrm{F}=$ 8.932 or 8.549 , respectively; $p<0.01)$. EPSP amplitude in $25-\mathrm{HT}+$ SEN Ab $(26-28 \mathrm{~h})$ or Cont + SEN Ab $(26-28 \mathrm{~h}$ ) treatments was not significantly different from that in control. The increase EPSP amplitude produced by 25 -HT was not significantly different from the increase produced by $25-\mathrm{HT}+\mathrm{SEN}$ Ab $(18-20 \mathrm{~h})$. By day 7 , only the increase in EPSP amplitude produced by $25-\mathrm{HT}$ or $25-\mathrm{HT}+\mathrm{SEN} \mathrm{Ab}(18-20 \mathrm{~h})$ persisted and was significantly greater than that of the other groups $(p<0.01)$, whereas the increase with 25 -HT was not significantly different from that with 25 -HT + SEN Ab $(18-20 \mathrm{~h}) .5 \times 5$-HT, Five bath applications of $5 \mu \mathrm{M}$ 5 -HT (each lasting $5 \mathrm{~min}$ ) at $20 \mathrm{~min}$ intervals.

Unlike the requirement for PI3K activity to produce LTF by 1 5-HT, PI3K activity during the second set of 5-HT treatments is no longer required for persistent LTF (Fig. 5). As reported previously (Hu et al., 2004a, 2006), blocking PI3K activity with PI3KI $(10 \mu \mathrm{M})$ during the single set of 5-HT treatments [1 5-HT + PI3KI $(24-26 \mathrm{~h}) ; n=6]$ inhibited the entire increase in EPSP amplitude on day 3 by 15 -HT alone $(n=12 ; 101 \pm 6.4 \%$ compared to $138 \pm 6.1 \% ; p<0.05)$. The EPSP amplitude with 15 -HT + PI3KI (24-26 h) was not significantly different from that of control $(98 \pm 3.9 \% ; n=11)$ or control with PI3KI [Cont + PI3KI (24-26 h); $97 \pm 5.4 \% ; n=6]$. In contrast, blocking PI3K activity during the second set of 5-HT treatments [2 5-HT + PI3KI $(24-26 \mathrm{~h}) ; n=9$ ] did not affect the increase in EPSP amplitude by 25 -HT alone $(n=14)$ on day 3 . This increase in EPSP amplitude (with PI3K inhibitor applied during the second set of 5-HT treatments) was not significantly different from the increase produced by 25 -HT alone $(161 \pm 8.5 \%$ compared to $173 \pm 9.2 \%)$ and persisted to day $7(139 \pm 6.0 \%)$, where it was significantly greater $(p<0.01)$ than the changes in EPSP amplitude in control or the various 15 -HT groups and was not significantly different from that produced by 25 -HT alone $(146 \pm 9.2 \%)$.
Persistent LTF induced by 25 -HT was blocked when PI3K inhibitor LY294002 was applied during the first set of 5-HT treatments (Fig. 5B). Adding the PI3K inhibitor during the first of the two sets of 5 -HT treatments $(0-2 \mathrm{~h})$ did not interfere with the increase in EPSP amplitude on day 3 that was produced by the second set of 5-HT treatments ( $145 \pm 9.7 \% ; n=13$ ) but blocked persistent LTF monitored on day 7 (95 $\pm 7.9 \%)$. Although PI3K activity during the second set of treatments is not required for persistent LTF, its actions during the first set of 5-HT treatments is required for the second set of 5-HT treatments to produce persistent LTF.

The failure of applied PI3K inhibitor during the second set of 5-HT treatments to block the persistent increase in EPSP amplitude paralleled the failure of the PI3K inhibitor to block the increase in sensorin expression immediately after the second set of 5-HT treatments (Fig. 6). In the presence of PI3K inhibitor during the second set of 5-HT treatments ( $24-26 \mathrm{~h} ; n=8)$, staining intensity of sensorin compared to control (normalized to $100 \% ; n=8$ ) remained significantly greater in the cell bodies (245 \pm $7.1 \%$ compared to $253 \pm 9.2 \%$ for $25-\mathrm{HT}$ alone; $n=8$ ), axons ( $201 \pm 7.3 \%$ compared to $205 \pm 16.5 \%$ for $25-\mathrm{HT}$ ), or varicosities ( $300 \pm 10.4 \%$ compared to $309 \pm 14.4 \%$ for 2 5-HT). Thus, persistent LTF induced by 2 5-HT does not require PI3K activity during the second set of 5-HT treatments but may recruit another signaling pathway to regulate the expression of sensorin required for persistent LTF. Since PKC activity regulates sensorin expression after another form of stimuli that produces an associative form of LTF at sensory neuron synapses (Hu et al., 2007), we examined whether PKC activity is required to produce persistent LTF by regulating sensorin expression after the second set of 5-HT treatments.

Blocking PKC activity with PKC inhibitor chelerythrine (PKCI; $10 \mu \mathrm{M}$ ) during the second set of 5-HT treatments [2 5-HT + PKCI $(24-26 \mathrm{~h}) ; n=8$ ] not only abolished the additional increase in EPSP amplitudes on day 3 produced by the second set of 5-HT treatments, but also evoked a rapid return of EPSP amplitude to baseline levels ( $96 \pm 6.3 \%$ ) (Fig. 7) compared to control $(98 \pm 9.8 \% ; n=6)$ and control with PKCI [Cont + PKCI $(24-26 \mathrm{~h}) ; 97 \pm 9.6 \% ; n=6]$. Treatment with 25 -HT alone $(n=$ 7) or with PKCI added either during the first set of 5-HT treatments [2 5-HT + PKCI $(0-2 \mathrm{~h}) ; n=6]$ or $4 \mathrm{~h}$ before the second set of 5-HT treatments $(18-20 \mathrm{~h} ; n=6)$ all evoked LTF both on day $3(176 \pm 5.7 \%, 172 \pm 7.0 \%$, and $173 \pm 5.5 \%$ increase in EPSP amplitude, respectively) and on day $7(145 \pm 9.3 \% .141 \pm 8.9 \%$, and $142 \pm 10.2 \%$, respectively) that were significantly greater $(p<0.01)$ than the changes evoked on day 3 or on day 7 by control treatments or when the PKC inhibitor was applied during the second set of 5-HT treatments. In contrast, blocking PKC activity either during the single set of 5-HT treatments [1 5-HT + PKCI $(24-26 \mathrm{~h}) ; n=6]$ or $24 \mathrm{~h}$ after $15-\mathrm{HT}(48-50 \mathrm{~h} ; n=6) \mathrm{did}$ 
not interfere with the increase in EPSP amplitude produced by the single set of 5 -HT treatments $(n=7)$ on day $3(139 \pm$ $4.5 \%$ or $141 \pm 6.0 \%$ compared to $138 \pm$ $3.8 \%$ for $15-\mathrm{HT})$. Change in EPSP amplitudes on day 3 for all $15-\mathrm{HT}$ treatment groups were significantly greater than those of various control groups $(p<0.05)$ or $25-\mathrm{HT}+\mathrm{PKCI}(24-26 \mathrm{~h})$ when the PKC inhibitor was added during the second set of 5 -HT treatments $(p<0.05)$. EPSP amplitudes for all 15 -HT treatment groups returned to control baseline level on day 7 . Thus, PKC activity during the second, but not first, set of 5-HT treatments is critical for the expression of persistent LTF. The labile nature of the initial LTF is expressed only when PKC inhibitor was added during the second set of 5-HT treatments. PKC activity during or at $24 \mathrm{~h}$ after $15-\mathrm{HT}$ does not affect the time course of the initial LTF produced by the single set of 5-HT treatments.

Blocking PKC activity during the second set of 5-HT treatments also blocked the rapid increase in sensorin expression produced by 2 5-HT (Fig. 8). Cultures were fixed and processed for sensorin immunochemistry immediately after or $2 \mathrm{~h}$ after the second set of 5-HT treatments [control, 2 5 -HT plus the indicated treatments, or 2 5-HT $(28 \mathrm{~h})]$. Immediately after 2 5-HT $(n=8)$, sensorin staining increased significantly in cell bodies ( $249 \pm 12.5 \%)$, axons $(221 \pm 17.1 \%)$, and varicosities $(294 \pm$ $17.0 \%$ ) compared to control (normalized to $100 \% ; n=8)$. Two hours after the second set of 5-HT treatments [2 5-HT (28 h); $n=$ $8]$, sensorin staining in the axons $(96 \pm$ $7.4 \%)$ and varicosities $(102 \pm 6.3 \%)$ returned to control levels, suggesting that the newly synthesized sensorin was secreted. This result is consistent with the observation that exogenous SEN Ab abolished the persistent LTF produced by 2 5-HT (Fig. 4). The increase in sensorin expression was blocked when PKCI $(10 \mu \mathrm{M})$ was added during the second set of 5-HT treatments [25-HT + PKCI (24-26); $n=8]$, but not during the first set of 5-HT treatments [2 5-HT + PKCI $(0-2 \mathrm{~h}) ; n=8]$. When PKCI was applied during the second set of 5-HT treatments, sensorin staining in the cell bodies ( $96 \pm 8.1 \%$ ), axons ( $89 \pm 3.2 \%$ ), and varicosities $(91 \pm 3.6 \%)$ were at control levels. The increase in sensorin staining with 2 5-HT was unaffected when PKCI was applied during the first set of 5 -HT treatments $(254 \pm 7.9 \%$ in the cell bodies; $222 \pm 8.6 \%$ in the axons; $284 \pm 15.8 \%$ in the varicosities). Both the increases in sensorin expression and persistent LTF require the activation of PKC during the second set of stimuli. Thus, persistent LTF requires both PI3K activity during the first set of 5-HT treatments to induce the first round of increased sensorin expression and PKC activity during the second set of 5-HT treatments to induce a second round of increased sensorin expression for subsequent secretion and downstream signaling.

\section{Discussion}

Our results address the question of whether the enhancement of long-term synaptic plasticity at an identified synapse with addi- tional stimulation requires the contributions of the same molecules and signaling pathways activated with the initial formation of the long-term synaptic plasticity. Our findings indicate that additional stimuli prolong the duration of LTF by recruiting a new signaling pathway to regulate the persistent expression of the same neurotrophin-like peptide (sensorin) that was used to initiate LTF with a single stimulus. In addition, our results indicate that the additional stimuli that prolong LTF also make the preexisting plasticity susceptible to complete disruption-a cellular phenomenon reminiscent of behavioral reconsolidation- by the timely blockade of either protein synthesis, the downstream signaling by sensorin, or the new signaling pathway (PKC) activated by the additional stimuli.

\section{A second round of sensorin synthesis and secretion by additional stimuli regulate the duration of LTF}

The number and the pattern of stimuli often regulate the duration of memory, behavioral change, or synaptic plasticity. Shortlasting change (lasting $<1 \mathrm{~h}$ ) does not typically require new macromolecular synthesis and mechanisms that in many cases are triggered in parallel with those required for the expression of long-term memory or synaptic plasticity (Emptage and Carew, 1993; McGaugh, 2000). Long-term memory/plasticity requires changes in the expression of proteins and genes, but may not lead 
A
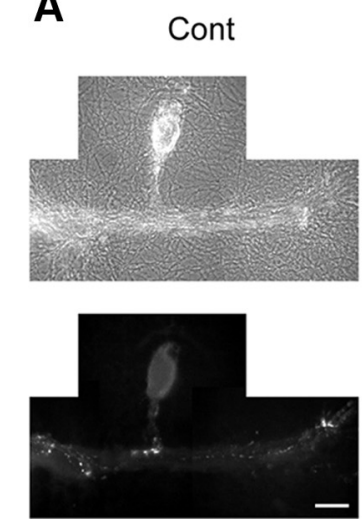

25-HT
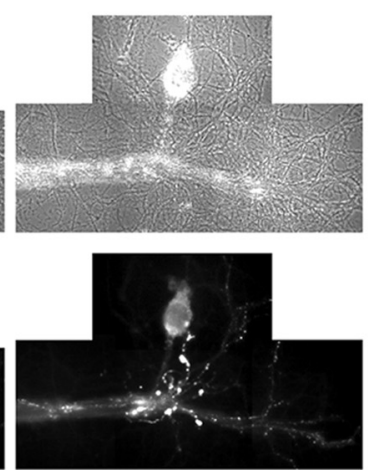

$25-\mathrm{HT}+$

PI3KI (24-26h)
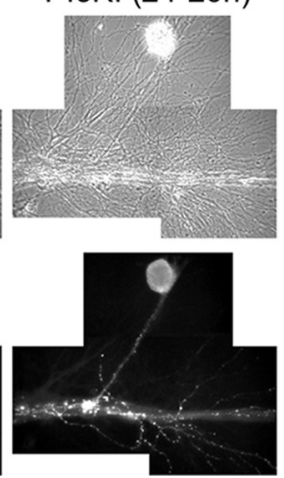

B

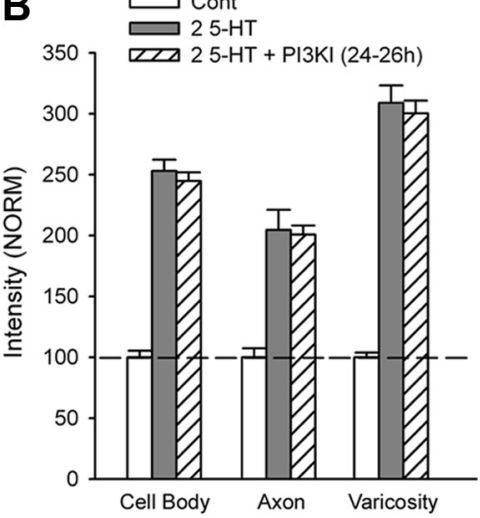

Figure 6. PI3K inhibitor failed to interfere with the increase in sensorin expression immediately after the second set of 5-HT treatments. $A$, Phase contrast and epifluorescent views of sensorin staining in the various compartments of sensory neurons indicated that sensorin staining increased in all compartments both in the absence or presence of PI3KI. Scale bar, $50 \mu \mathrm{m}$. B, Summary of sensorin staining in all compartments after treatments. An ANOVA indicated a significant effect of treatment ( $\mathrm{df}=4,42 ; F=27.71 ; p<0.001$ ). Individual comparisons indicated that compared to control, the other treatments evoked significant increases in all compartments $(F=20.424-108.692 ; p<0.01)$. Sensorin staining for cultures treated with $5-\mathrm{HT}$ in the absence or presence of PI3KI was not significantly different across compartments.

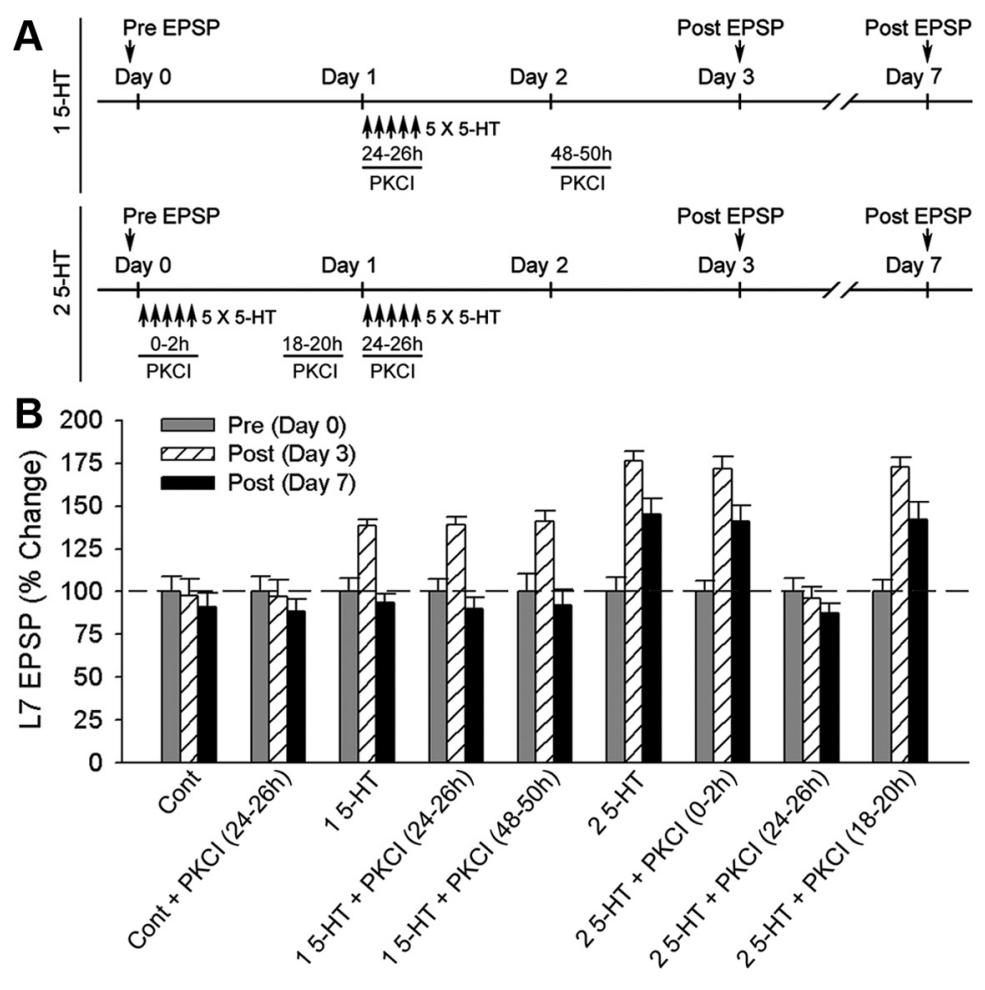

Figure 7. PKC activity during the second set, but not the first set, of 5-HT treatments is required for persistent LTF. $\boldsymbol{A}$, Time line of treatments indicating when $15-\mathrm{HT}, 25-\mathrm{HT}$, and PKCI were applied and EPSPs were tested. $\boldsymbol{B}$, Summary of the changes in EPSP amplitudes. An ANOVA indicated a significant effect of treatment ( $\mathrm{df}=16,98 ; F=26.572 ; p<0.001$ ). Individual comparisons indicated that the following treatments produced a significant increase in EPSP amplitude on day 3 compared to control, as well as produced a significant increase compared to Cont $+\mathrm{PKCl}(24-26 \mathrm{~h} ; F=2.322-8.907$; $p<0.05$ or 0.01$): 15-\mathrm{HT}(F=2.338 ; p<0.05), 15-\mathrm{HT}+\mathrm{PKCl}(24-26 \mathrm{~h}, F=2.267, p<0.05 ; 48-50 \mathrm{~h}, F=2.511, p<$ $0.05), 25-\mathrm{HT}(F=8.794 ; p<0.01)$, and $25-\mathrm{HT}+\mathrm{PKCl}(0-2 \mathrm{~h}, F=7.923, p<0.01 ; 18-20 \mathrm{~h}, F=7.336, p<0.01)$. The change in EPSP amplitude produced by application of PKCI during the second set of 5-HT treatments ( $24-26 \mathrm{~h}$ ) was not significantly different from control, but was significantly smaller than the changes produced by the other $25-\mathrm{HT}$ treatment groups $[25-\mathrm{HT}, F=10.544 ; 25-\mathrm{HT}+\mathrm{PKCl}(0-2 \mathrm{~h}), F=9.311 ; 25-\mathrm{HT}+\mathrm{PKCl}(18-20 \mathrm{~h}), F=9.022 ; p<0.01)]$ and the various 15 -HT treatment groups $(F=2.777-3.065 ; p<0.05)$. The changes produced by 25 -HT were not significantly different from those by $25-\mathrm{HT}+\mathrm{PKCl}(0-2$ and $18-20 \mathrm{~h})$. By day 7 , the increase in EPSP amplitude produced by all $25-\mathrm{HT}$ treatments groups except for $25-\mathrm{HT}+\mathrm{PKCl}(24-26 \mathrm{~h})$ persisted and were significantly greater than those produced in the other groups $(p<0.01)$. The increase in EPSP amplitude with $25-\mathrm{HT}$ was not significantly different from that with 25-HT + PKCI $(0-2$ or $18-20$ h). The EPSP amplitude with $25-\mathrm{HT}+$ PKCI $(24-26 \mathrm{~h})$ was back to control level and not significantly different from those in control or all 15 -HT treatment groups. $5 \times 5$-HT, Five bath applications of $5 \mu \mathrm{m} 5$-HT (each lasting $5 \mathrm{~min}$ ) at $20 \mathrm{~min}$ intervals. to a persistent change in behavior or the properties of the activated neurons (Pinsker et al., 1973; Martin et al., 1997; Sun and Schacher, 1998; Miniaci et al., 2008). The varying duration of long-term plasticity may reflect the requirement for waves of required macromolecular synthesis to regulate the time course of the plasticity (Miniaci et al., 2008; Liu et al., 2008). Although the mechanism mediating the decay of memory or long-term plasticity is not known, it may not require a complete reversal of the molecular changes (gene and protein expression) but lead either to a selective loss of the most recent cellular changes induced by the stimuli or to a general decline of cellular properties to mediate a return to prestimulated levels (Grabham et al., 2005; Miniaci et al., 2008). Our results indicate that the additional stimuli block or postpone the reversal of the synaptic change back to baseline and induce a more persistent change by recruiting a new signaling pathway to regulate the expression of the neurotrophin-like peptide sensorin. Interestingly, when inhibitors applied during the additional stimuli disrupt persistent LTF, EPSP amplitude rapidly returns to the initial baseline and is maintained at that level as observed for other controls.

Once long-term memory is either initiated or fully consolidated, additional training activates some of the same molecular pathways as those recruited during earlier training sessions (for review, see Nader and Hardt, 2009; Nader and Einarsson, 2010; Inda et al., 2011). These might include activation of specific glutamate receptors, secretion and downstream signaling of growth factors, and the activation of transcription factors. The presence of specific inhibitors during additional training 
A
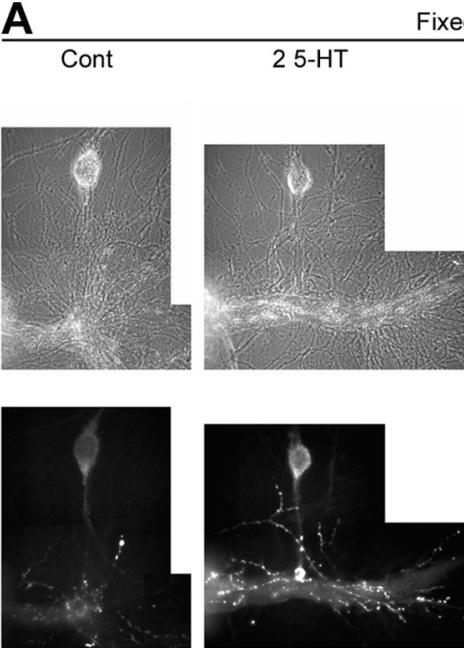

B

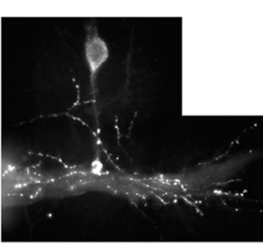
(1)

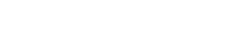

Fixed at $26 \mathrm{~h}$
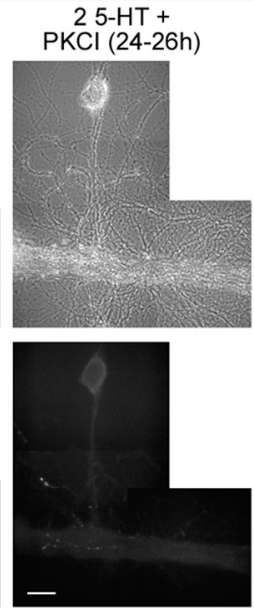

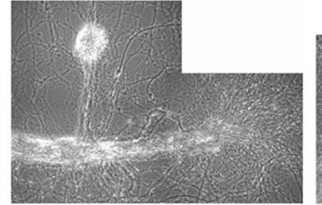

$\mathrm{PKCl}(0-2 \mathrm{~h})$

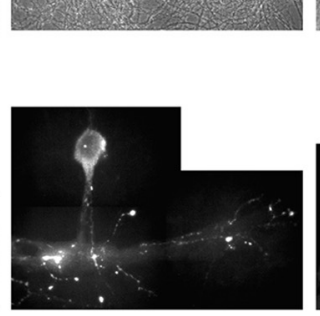

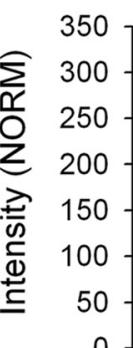

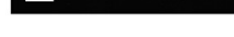

Cont

区Xय 2 5-HT (28h)

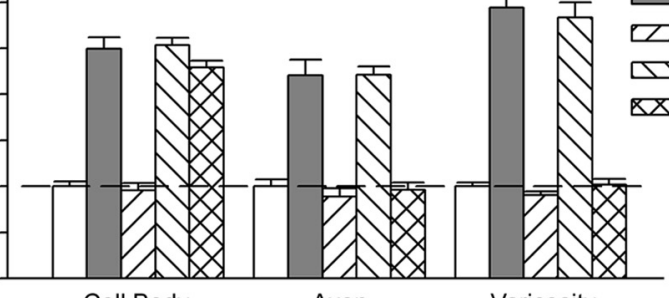

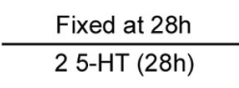

2 5-HT (28h)
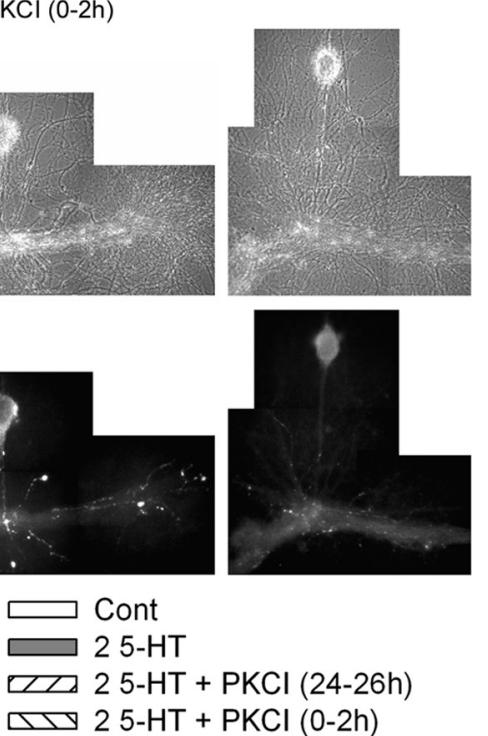

$\triangle 25-\mathrm{HT}+\mathrm{PKCl}(0-2 \mathrm{~h})$

Cell Body

Axon

Varicosity

Figure 8. PKC activity during the second set of 5-HT treatments is required for the increase in sensorin expression. $\boldsymbol{A}$, Phase contrast (top) and epifluorescent views (bottom) of sensorin immunostaining in cocultures fixed and processed for sensorin staining immediately or $2 \mathrm{~h}$ after the second set of 5 - $\mathrm{HT}$ treatments in the absence or presence of PKCl applied at the indicated times. Sensorin staining in the varicosities and axons $2 \mathrm{~h}$ after the second set of 5 - $\mathrm{HT}$ treatments [ $25-\mathrm{HT}$ ( $28 \mathrm{~h}$ )] was reduced back to control levels, consistent with the secretion of the newly synthesized peptide from distal portions of the sensory neuron (Fig. 4). PKCl applied during the second set of 5-HT treatments [25-HT + PKCl (24-26 h)] blocked the increase in sensorin expression immediately after the second set of 5 - $\mathrm{HT}$ treatments, whereas application of PKCl during the first set of 5 - $\mathrm{HT}$ treatments [25-HT $+\mathrm{PKCl}(0-2 \mathrm{~h})]$ failed to interfere with the increase in sensorin expression. Scale bar, $50 \mu \mathrm{m} . B$, Summary of the changes in sensorin staining in each compartment. An ANOVA indicated a significant effect of treatment (df $=8,70 ; F=59.918 ; p<0.001$ ). Compared to control, $25-\mathrm{HT}$ and $25-\mathrm{HT}+\mathrm{PKCl}(0-2 \mathrm{~h})$ significantly increase sensorin expression in all compartments $(F=18.723-40.67 ; p<0.01)$. Treatment with PKCl during the second set of 5-HT treatments blocked the increase in sensorin expression in all compartments, and the intensity was not significantly different from control. Sensorin staining for 25 - $\mathrm{HT}+\mathrm{PKCl}(24-26 \mathrm{~h}$ ) was significantly lower in each compartment than the staining for $25-\mathrm{HT}$ and $25-\mathrm{HT}+\mathrm{PKCl}(0-2 \mathrm{~h} ; F=20.118-43.022 ; p<0.01)$.

leads to a disruption of the behavioral plasticity. It is not clear, however, whether the reactivation and/or inhibition of these pathways affect cellular changes in the previously activated neurons. Our results with a two-neuron circuit suggest that the labile nature of preexisting plasticity with additional stimuli is an intrinsic property of the reactivated neurons.

The neuropeptide sensorin is synthesized in the mechanosensory neurons of Aplysia (Brunet et al., 1991), and its secretion is required to initiate $\mathrm{LTF}$ ( $\mathrm{Hu}$ et al., 2004a, 2006). Its role is reminiscent of that played by BDNF in producing long-lasting forms of long-term potentiation in hippocampus (Lee et al., 2004; Soulé et al., 2006; Lu et al., 2008). The initial treatments with 5-HT evoke a rapid increase in sensorin synthesis, and the rapid secretion of the newly synthesized sensorin is required for LTF monitored at $24 \mathrm{~h}$ (Hu et al., 2004a, 2006). Sensorin expression then rises to $\sim 100 \%$ over control at $12 \mathrm{~h}$ after 5 -HT stimulation (Hu et al., 2006), but then declines to $\sim 30-40 \%$ above control at $24 \mathrm{~h}$ (Fig. 3). This reduction in sensorin levels may contribute to the failure to maintain synaptic plasticity much beyond 3-4 $\mathrm{d}$ after 1 5-HT. Levels of sensorin expression correlate with levels of sensorin secretion, and sensorin secretion and downstream signaling are critical for maintaining synaptic baseline (Hu et al., 2002, 2004a,b, 2006). Blocking constitutive and persistent downstream signaling by secretion of sensorin might lead to retraction of sensory neuron branches, loss of varicosities, and reduction in synaptic effi- cacy (Hu et al. 2006). Moreover, blocking the downstream actions of the newly synthesized sensorin secreted immediately after the second set of 5-HT treatments also abolished persistent LTF (Fig. 4), indicating that the downstream actions of newly synthesized sensorin contribute to the formation of persistent LTF.

The second set of 5-HT treatments that produces persistent LTF induces a second round of rapid synthesis and secretion of sensorin followed by a high level of constitutive expression of sensorin even after $24 \mathrm{~h}$. Rapamycin or PKC inhibitor applied during the second set of 5-HT treatments leads to a rapid reduction in sensorin levels, and this low level of sensorin expression is maintained $1 \mathrm{~d}$ later. This rapid decline of sensorin expression to control prestimulation levels correlates with the rapid return to synaptic baseline by day 3 . Thus, the failure to maintain a high level of sensorin expression and secretion may contribute to the rapid disruption of LTF.

\section{PKC activation is required to regulate the second round of} sensorin expression and persistent LTF

A new signaling pathway involving the activation of PKC during the second set of 5-HT treatments is required for persistent LTF and contributes to the rapid and persistent increase in sensorin expression. PI3K activity during the first set of 5-HT treatments regulates the first round of rapid synthesis of sensorin ( $\mathrm{Hu}$ et al., 2006). This first round of enhanced synthesis (and subsequent 
secretion) is required to initiate LTF and contributes, along with the second round of increased synthesis and secretion evoked by second set of 5-HT treatments, to the formation of persistent LTF. Blocking PKC during the first set of 5-HT treatments not only failed to block the initial rapid increase in sensorin expression and LTF at $24 \mathrm{~h}$ (Hu et al., 2006), but also failed to block persistent LTF and the increase in sensorin expression produced by adding a second set of 5-HT treatments. In contrast, blocking PKC, but not PI3K, activity during the second set of 5-HT treatments not only blocked persistent LTF but also produced a premature return to control levels for both synaptic strength and sensorin expression. PI3K activity during the second set of 5-HT treatments is not essential for persistent LTF or changes in sensorin expression. Thus, the need to recruit a new signaling pathway by the additional stimuli for maintaining high levels of constitutive sensorin expression may contribute to the labile nature of the preexisting plasticity.

The recruitment of PKC activity may result from an increase in the expression of 5-HT receptors linked to PKC in sensory neurons or L7 (Li et al., 1995) after the first set of 5-HT treatments. The second set of 5-HT treatments now activates a PKC pathway affecting sensorin synthesis. A single temporal pairing of activity in the sensory neuron with a 5-HT application leads to a rapid PKC- and rapamycin-dependent increase in the synthesis of sensorin required to produce an associative form of LTF (Hu et al., 2007). Interestingly, PI3K activity is not required to regulate the rapid synthesis of sensorin with paired stimulation. Associative LTF produced by a single pairing and persistent LTF produced by two sets of nonassociative stimuli may activate the activities of the same or different PKC isoforms that converge to regulate the rapid synthesis of sensorin. The PKC activity may be induced in the sensory neuron (Manseau et al., 2001; Zhao et al., 2006) to regulate both the rapid and persistent translation of sensorin mRNA distributed throughout the sensory neuron $(\mathrm{Hu}$ et al., 2002, 2006; Lyles et al., 2008) by a cytoplasmic polyadenylation element binding protein (CPEB)-dependent and/or CREBdependent mechanisms. The activation of transcription factors such as CREB and CCAAT/enhancer binding protein and regulators of protein synthesis such as $\mathrm{CPEB}$ contribute to functional and structural changes associated with persistent synaptic plasticity in both invertebrates and vertebrates (Alberini et al., 1995; Yin and Tully, 1996; Taubenfeld et al., 2001; Liu et al., 2008; Miniaci et al., 2008; Richter and Klann, 2009; Chen et al., 2011). Alternatively, the PKC activity may be induced in the motor neuron L7 (Villareal et al., 2009) to generate a retrograde signal to regulate sensorin synthesis in the sensory neuron. During early stages of synapse maturation, the activation of a novel PKC in L7 regulates sensorin expression in sensory neurons (Hu et al., 2010). The second set of 5-HT treatments may also recruit the activation of an atypical PKC (Bougie et al., 2009). An atypical PKC plays a critical role in persistent LTP in hippocampus and other regions of the mammalian brain and in persistent memory (Shema et al., 2007; Yao et al., 2008).

In conclusion, our results suggest that a persistent form of synaptic plasticity induced by multiday exposures to stimuli is produced by the sequential activation of signaling cascades that regulate the synthesis and secretion of a neurotrophin-like neuropeptide, sensorin. Early stimuli not only activate PI3K to regulate the first round of sensorin synthesis, whose secretion initiates a short-lasting form of LTF, but also primes this synapse to respond to subsequent stimuli to produce a persistent LTF by activating a different signaling pathway (PKC) to induce a more persistent increase in sensorin synthesis. In the course of activat- ing this new signaling pathway by additional stimuli, the initial plasticity becomes labile and susceptible to disruption by the timely presence of inhibitors of protein synthesis, PKC activity, or the downstream signaling by sensorin.

\section{References}

Abel T, Lattal KM (2001) Molecular mechanisms of memory acquisition, consolidation and retrieval. Curr Opin Neurobiol 11:180-187.

Alberini CM (2005) Mechanisms of memory stabilization: are consolidation and reconsolidation similar or distinct processes? Trends Neurosci 28:51-56.

Alberini CM (2011) The role of reconsolidation and the dynamic process of long-term memory formation and storage. Front Behav Neurosci 5:12.

Alberini CM, Ghirardi M, Huang YY, Nguyen PV, Kandel ER (1995) A molecular switch for the consolidation of long-term memory: cAMPinducible gene expression. Ann N Y Acad Sci 758:261-286.

Bailey CH, Chen M (1989) Time course of structural changes at identified sensory neuron synapses during long-term sensitization in Aplysia. J Neurosci 9:1774-1780.

Bailey CH, Chen M, Montarolo PG, Kandel ER Schacher S (1992) Inhibitors of protein and RNA synthesis block structural and functional change accompanying long-term synaptic facilitation and inhibition in Aplysia sensory neurons. Neuron 9:749-758.

Bougie JK, Lim T, Farah CA, Manjunath V, Nagakura I, Ferraro GB, Sossin WS (2009) The atypical protein kinase C in Aplysia can form a protein kinase M by cleavage. J Neurochem 109:1129-1143.

Brunet JF, Shapiro E, Foster SA, Kandel ER, Iino Y (1991) Identification of a peptide specific for Aplysia sensory neurons by PCR-based differential screening. Science 252:856-859.

Castellucci VF, Blumenfeld H, Goelet P, Kandel ER (1989) Inhibitor of protein synthesis blocks long-term behavioral sensitization in the isolated gill-withdrawal reflex of Aplysia. J Neurobiol 20:1-9.

Chen DY, Stern SA, Garcia-Osta A, Saunier-Rebori B, Pollonini G, BambahMukku D, Blitzer RD, Alberini CM (2011) A critical role for IGF-II in memory consolidation and enhancement. Nature 469:491-497.

Davis HP, Squire LR (1984) Protein synthesis and memory: a review. Psychol Bull 96:518-559.

Dudai Y (2004) The neurobiology of consolidations, or, how stable is the engram? Annu Rev Psychol 55:51-86.

Eliot LS, Hawkins RD, Kandel ER, Schacher S (1994) Pairing-specific, activity-dependent presynaptic facilitation at Aplysia sensory-motor neuron synapses in isolated cell culture. J Neurosci 14:368-383.

Emptage NJ, Carew TJ (1993) Long-term synaptic facilitation in the absence of short-term facilitation in Aplysia neurons. Science 262:253-256.

Frost WN, Castellucci VF, Hawkins RD, Kandel ER (1985) Monosynaptic connections made by the sensory neurons of the gill- and siphonwithdrawal reflex in Aplysia participate in the storage of long-term memory for sensitization. Proc Natl Acad Sci U S A 82:8266-8829.

Glanzman DL, Mackey SL, Hawkins RD, Dyke AM, Lloyd PE, Kandel ER (1989) Depletion of serotonin in the nervous system of Aplysia reduces the behavioral enhancement of gill withdrawal as well as the heterosynaptic facilitation produced by tail shock. J Neurosci 9:4200-4213.

Glanzman DL, Kandel ER, Schacher S (1990) Target-dependent structural changes accompanying long-term synaptic facilitation in Aplysia neurons. Science 249:799-802.

Goelet P, Castellucci VF, Schacher S, Kandel ER (1986) The long and the short of long-term memory-a molecular framework. Nature 322:419-422.

Grabham PW, Wu F, Schacher S, Goldberg DJ (2005) Initiating morphological changes associated with long-term facilitation in Aplysia is independent of transcription and translation in the cell body. J Neurobiol 64:202-212.

Hu JY, Meng X, Schacher S (2002) Target interaction regulates distribution and stabilitiy of specific mRNAs. J Neurosci 22:2669-2678.

Hu JY, Glickman L, Wu F, Schacher S (2004a) Serotonin regulates the secretion and autocrine action of a neuropeptide to activate MAPK required for long-term facilitation in Aplysia. Neuron 43:373-385.

Hu JY, Goldman J, Wu F, Schacher S (2004b) Target-dependent release of a presynaptic neuropeptide regulates the formation and maturation of specific synapses in Aplysia. J Neurosci 24:9933-9943.

Hu JY, Wu F, Schacher S (2006) Two signaling pathways regulate the ex- 
pression and secretion of a neuropeptide required for long-term facilitation in Aplysia. J Neurosci 26:1026-1035.

Hu JY, Chen Y, Schacher S (2007) Protein kinase C regulates synthesis and secretion of a neuropeptide required for activity-dependent long-term synaptic facilitation. J Neurosci 27:8927-8939.

Hu JY, Chen Y, Bougie JK, Sossin WS, Schacher S (2010) Aplysia cell adhesion molecule and a novel protein kinase $\mathrm{C}$ activity in the postsynaptic neuron are required for presynaptic growth and initial formation of specific synapses. J Neurosci 30:8353-8366.

Inda MC, Muravieva EV, Alberini CM (2011) Memory retrieval and the passage of time: from reconsolidation and strengthening to extinction. J Neurosci 31:1635-1643.

Kandel ER (2001) The molecular biology of memory storage: a dialogue between genes and synapses. Science 294:1030-1038.

Lee JL, Everitt BJ, Thomas KL (2004) Independent cellular processes for hippocampal memory consolidation and reconsolidation. Science 304:839-843.

Li XC, Giot JF, Kuhl D, Hen R, Kandel ER (1995) Cloning and characterization of two related serotonergic receptors from the brain and the reproductive system of Aplysia that activate phospholipase C. J Neurosci 15:7585-7591.

Liu K, Hu JY, Wang D, Schacher S (2003) Protein synthesis at synapse versus cell body: enhanced but transient expression of long-term facilitation at isolated synapses. J Neurobiol 56:275-286.

Liu RY, Fioravante D, Shah S, Byrne JH (2008) cAMP response elementbinding protein 1 feedback loop is necessary for consolidation of longterm synaptic facilitation in Aplysia. J Neurosci 28:1970-1976.

Lu Y, Christian K, Lu B (2008) BDNF: a key regulator for protein synthesisdependent LTP and long-term memory? Neurobiol Learn Mem 89:312-323.

Lyles V, Zhao Y, Martin KC (2008) Synapse formation and mRNA localization in cultured Aplysia neurons. Neuron 49:349-356.

Manseau F, Fan X, Hueftlein T, Sossin W, Castellucci VF (2001) Ca2+independent protein kinase C Apl II mediates the serotonin-induced facilitation at depressed Aplysia sensorimotor synapses. J Neurosci 21:1247-1256.

Marinesco S, Carew TJ (2002) Serotonin release evoked by tail nerve stimulation in the CNS of aplysia: characterization and relationship to heterosynaptic plasticity. J Neurosci 22:2299-2312.

Martin KC, Casadio A, Zhu H, Rose JC, Chen M, Bailey CH, Kandel ER (1997) Synapse-specific long-term facilitation of Aplysia sensory somatic synapses: a function for local protein synthesis in memory storage. Cell 91:927-938.

McGaugh JL (2000) Memory-a century of consolidation. Science 287: $248-251$.

Miniaci MC, Kim JH, Puthanveettil SV, Si K, Zhu H, Kandel ER, Bailey CH (2008) Sustained CPEB-dependent local protein synthesis is required to stabilize synaptic growth for persistence of long-term facilitation in Aplysia. Neuron 59:1024-1036.

Montarolo PG, Goelet P, Castellucci VF, Morgan J, Kandel ER, Schacher S (1986) A critical period for macromolecular synthesis in long-term heterosynaptic facilitation in Aplysia. Science 234:1249-1254.

Nader K, Einarsson EO (2010) Memory reconsolidation: an update. Ann N Y Acad Sci 1191:27-41.
Nader K, Hardt O (2009) A single standard for memory: the case for reconsolidation. Nat Rev Neurosci 10:224-234.

Nader K, Schafe GE, LeDoux JE (2000) Fear memories require protein synthesis in the amygdala for reconsolidation after retrieval. Nature 406:722-726.

O'Leary FA, Byrne JH, Cleary LJ (1995) Long-term structural remodeling in Aplysia sensory neurons requires de novo protein synthesis during a critical time period. J Neurosci 15:3519-3525.

Pinsker HM, Hening WA, Carew TJ, Kandel ER (1973) Long-term sensitization of a defensive withdrawal reflex in Aplysia. Science 182:1039-1042.

Rayport SG, Schacher S (1986) Synaptic plasticity in vitro: Cell culture of identified Aplysia neurons mediating short-term habituation and sensitization. J Neurosci 6:759-763.

Reijmers LG, Perkins BL, Matsuo N, Mayford M (2007) Localization of a stable neural correlate of associative memory. Science 317:1230-1233.

Richter JD, Klann E (2009) Making synaptic plasticity and memory last: mechanisms of translational regulation. Genes Dev 23:1-11.

Schacher S, Montarolo PG (1991) Target-dependent structural changes in sensory neurons of Aplysia accompany long-term heterosynaptic inhibition. Neuron 6:679-690.

Shema R, Sacktor TC, Dudai Y (2007) Rapid erasure of long-term memory associations in the cortex by an inhibitor of PKMzeta. Science 317:951-953.

Soulé J, Messaoudi E, Bramham CR (2006) Brain-derived neurotrophic factor and control of synaptic consolidation in the adult brain. Biochem Soc Trans 34:600-604.

Sun ZY Schacher S (1998) Binding of serotonin to receptors at multiple sites is required for structural plasticity accompanying long-term facilitation of Aplysia sensorimotor synapses. J Neurosci 18:3991-4000.

Taubenfeld SM, Milekic MH, Monti B, Alberini CM (2001) The consolidation of new but not reactivated memory requires hippocampal C/EBPbeta. Nat Neurosci 4:813-818.

Villareal G, Li Q, Cai D, Fink AE, Lim T, Bougie JK, Sossin WS, Glanzman DL (2009) Role of protein kinase $\mathrm{C}$ in the induction and maintenance of serotonin-dependent enhancement of the glutamate response in isolated siphon motor neurons of Aplysia californica. J Neurosci 29:5100-5107.

Wang $\mathrm{H}, \mathrm{Hu} \mathrm{Y}$, Tsien JZ (2006) Molecular and systems mechanisms of memory consolidation and storage. Prog Neurobiol 79:123-135.

Xu T, Yu X, Perlik AJ, Tobin WF, Zweig JA, Kelly T, Jones T, Yi Z (2009) Rapid formation and selective stablization of synapses for enduring motor memories. Nature 462:915-919.

Yao Y, Kelly MT, Sajikumar S, Serrano P, Tian D, Bergold PJ, Frey JU, Sacktor TC (2008) PKM zeta maintains late long-term potentiation by N-ethylmaleimide-sensitive factor/GluR2-dependent trafficking of postsynaptic AMPA receptors. J Neurosci 28:7820-7827.

Yin JC, Tully T (1996) CREB and the formation of long-term memory. Curr Opin Neurobiol 6:264-268.

Zhao Y, Leal K, Abi-Farah C, Martin KC, Sossin WS, Klein M (2006) Isoform specificity of PKC translocation in living Aplysia sensory neurons and a role for $\mathrm{Ca} 2+$-dependent PKC APL I in the induction of intermediate-term facilitation. J Neurosci 26:8847-8856. 